\title{
Analysis on Method of Protection and Utilization for the Historical Building in Laojun Cave
}

\author{
Jihong Xiao, Xiangdong Zhu, Chongen Wang \\ College of Architecture and Civil Engineering, \\ Taiyuan University of Technology in Shanxi of China, 030024
}

\begin{abstract}
As one of the Taoist architectures in China, Laojun Cave possesses significant historical value, artistic value and scientific value. In order to effectively protect this cultural heritage with rich connotation and precious value, this paper explores how to play an active role of culture heritage in the modernization construction in a scientific, reasonable and moderate way, making overall arrangements for construction activities and conservation works, correctly dealing with the relation among historic preservation, surrounding villages and township development, the relation between historic preservation and rational utilization, and finally to promote sustainable development for cultural heritage protection and utilization.
\end{abstract}

Keywords-Historical building; Protection; utilization; Sustainable development

Located in Fushan, Linfen, Shanxi, LaoJun Cave of Fushan has been rated as the sixth national relic protection unit. Fushan is in the middle and lower reaches of Fen River in the east, just inside one of cradles of Chinese civilization, so the cultures from the Paleolithic Age to the Neolithic Age are successively. In the evolution of human civilizations over thousands of years, abundant historical site, remains have been left, spreading all over the counties and villages, equipped with high cultural deposits and architectural art. Among them, the most attractive one is religious architecture and cultures represented by national relic protection unit - Laojun Cave.

\section{The CONSERVATION VALUE OF LAOJUn CAVE}

\section{A. Historical Value}

Laojun Cave was constructed in the second year of Tang Takenori by the imperial edicts, which is the representative of the ancient Taoist buildings in our country. Emperor Gaozu formed the relationship of the same clan with Lao Tze, and made imperial edicts to construct Lao Tze temple in Yangjiao Mountain, and build 36 Taoist Temples such as Laojun Cave, San Qing Tien Taoist Temple, Tai Qing Taoist Temple, and Qing Jing Temple around, holding a memorial ceremony for them in four seasons. Taoism buildings in Fushan County area are numerous on a grand scale, which are regarded as the holy land of Taoism and the ancestor temples of emperors. Laojun Cave is the typical representative of Taoism buildings in this historical period.

\section{B. Artistic Value}

Laojun Cave is the living example of the rare stone beam shrines in existence in our country, carved by stones from stylobate to roof with great care. The structure of the whole shrine is unique with proper proportion, and the artistic expression is very exquisite. It is the typical building with stone as the main structure. The murals of Huang Lu Pilgrimage Figure on the walls of the shrine were facsimiled according to the murals painted by Wu Tao-tzu in San Qing Tien of Qingtang Guan Taoist Temple. The murals have a long history, with rich content, vigorous contours, coloring of primitive simplicity and vigor, and elegant and serene postures. These murals are not only the rare treasures of Taoism culture, but also the historical masterpieces of painting art, with significant value of cultural relics.

81 Lao Tze Manifest Paintings has been inset inside the great hall, composed by thirty-nine black jades, interpreting the immortal experience of Lao $\mathrm{Zi}$, with delicate blade and smooth lines. It has been deemed as the earliest large comic strip in China after identified by archaeologists and heritage experts, possessing the important religious and artistic value.

\section{Scientific Value}

Architecture is a concentrated reflection of science and technology achievements in its era as the carrier. After the Taoist architectures in Fushan area including Laojun Cave combined with the imperial power, it reflected the most advanced stone construction technology in the social conditions from another perspective. Blended Stone Beam Shrine is the main shrine of Laojun Cave, which was built over high platform, facing south, three rooms long, two rooms wide, with hip-and-gable roof with single eave. The shrine is 6.3 meters high, 10 meters wide. There are 22 stone corbel brackets before and after the shrine and 14 stone corbel brackets on both sides. There is a mullion window on both sides in the front of shrine, and a stone arch in the middle. The Stone Beam Shrine is of unique structure and reasonable design, mainly manifested in the stone construction of its beams, eaves, ridges, tiles and so one without woods or shingles, nor was it carved with stone. Such constitution is rare, reflecting ancient people's processing technique level and usage of stone materials, also reflecting people's building skills of using stone structure to imitate wood structure. So, Laojun Cave is of great reference value to studying the development level of science and technology at that time. 


\section{Social Value}

Laojun Cave is a classic example of Shanxi religious architecture, fully embodying its role as a cultural carrier in the process of historical development. What lies behind Laojun Cave are not only rich religious background and social cultural background such as Lao Tze making presence or power felt and finding origin, but also the folklores related to Laojun Cave. As a religious architecture, Laojun Cave was an important place for people to gather for religious activities and daily communication in the past. Laojun Cave is the important instance to study ancient stone architectures in Jinnan area, the place for people to understand and experience Chinese traditional architecture and religious culture, which has high social and cultural values in architecture research, cultural tourism and popularization of traditional architecture knowledge.

\section{PROBLEMS IN THE PROTECTION AND UTILIZATION OF FUSHANLAOJUN CAVITY}

The historical Building of Fushan County is a significant part of the country, as well as the important link of sustainable development. It is related to the vital interests of its descendants. Fushan County is now in rapid development stage, but the protection of historical Building is confronted by great threats, and there are mainly the following aspects of problems.

\section{A. Problem of Protecting the Authenticity}

The protection of various forms cultural heritage in different historic periods relies on the value of heritage. People's understanding of the value depends on the reliability of information source related to the value. Moreover, the understanding and comprehension of such information source is related to the initial and follow-up characteristics and significance of the cultural heritage, as the necessary foundation of the comprehensive assessment of the authenticity. However, at present, the protection of Laojun Cave pays no attention to the authenticity. Although there are no too many changes in the façade of construction, the original materials of the architecture is gradually replaced. Such protection actually causes severe destruction to the architecture, and it shall not be adopted.

\section{B. Disordered State of Protection and Updating}

With the development of the county and expansion of population, the villages and towns are in rapid development. Consequently, the increase of construction is quite widespread. With the coverage and occupation of historical buildings, destruction to the texture of the county and reduction of life and environmental quality, it is a disordered protection and updating state. However, the newly-built architectures fail to be in accordance with the historic architectures in scale, texture, color, etc. All these phenomena show that it is urgent to make targeted protection planning for guiding the protection and updating.

\section{Problem of Appropriate Re-Utilization and Sustainable Application}

Due to the lack of necessary limitation on application and correct guidance, Laojun Cave is completely in idle state, which even separates the close relationship between the architecture and human. The traditional architecture requires constant daily maintenance, and the idle state means abandoning, and giving up protection and updating. Seen from the entire region, the danger is greater, which may directly reduce the decline of the entire historic space. The insufficient excavation of the regional economic potential cannot reflect the due value of Laojun Cave. There is no doubt that the reutilization is the necessary demand of the future regional development. On the premise of protection, the appropriate, reasonable and sustainable utilization is the basic principle of reutilization.

\section{PRINCIPLE OF PRESERVATION AND Utilization FOR LAOJUN CAVE}

\section{A. Principle of Authenticity}

The authenticity reflects the historic, art and scientific value, and it is the key of historical relics. In order to protect the original authentic historic objects preserved, it shall protect the complete historic information. The renovation shall adopt the original materials, technology and forms to achieve the original taste and restore the original landscape.

\section{B. Principle of Readability}

The historical relics will leave the print of history, from which, the "historic annual ring" can be read directly. The readability means that the history can be read according to the historical relics. Namely, the prints left in different stages shall be admitted, instead of being wiped out according to the thoughts of modern people. The largescale demolition and reconstruction is not in line with the readability principle.

\section{Principle of Integrity}

The historical and cultural relics exist with the environment, therefore, the relics and its surrounding environment shall be protected. Only in this way, can it reflect the styles and features of the history. The integrality shall also include the cultural connotation and form the element, for instance, the block shall include the life activities of residents, as well as the related environment target. The target of protection is not simply the separate ancient architecture. More importantly, it shall be the complete system of the entire ancient architectural complex produced in specific natural and cultural background.

\section{Principle of Sustainability}

The protection of historical relics is a long-term cause. Once it is realized and determined, it shall be protected, and education shall be reinforced to continue the protection cause. During the planning, the uncertainty of various factors shall be considered, and elastic design method shall be adopted. 


\section{E. Principle of Harmony}

The renovation and maintenance of historic space shall be in accordance with the development of modern life, and it shall combine the protection and development. Consequently, comprehensive discrete long-term adjustment shall be carried out by stages. Meanwhile, according to the principle of authenticity, integrity and reality, the protection of Laojun Cave shall be combined to the local economic development, so as to promote each other and form the virtuous cycle of protection and utilization.

\section{F. Principle of Openness}

Through planning various kinds of open space, the residents may enjoy all kinds of communication and recreation space, in which, residents may appreciate and take entertainment activities. It may become the open space serving all residents.

\section{Measures and Methods of Preservation AND UTILIZATION FOR LAOJUN CAVE}

Based on the historical analysis, targeted protection and updating planning is made by analyzing the protection and reutilization stats of Laojun Cave. Meanwhile, attention shall be paid to the authenticity principle, and the modern extension and evolution of historic architecture shall be strengthened after proper renovation and updating. It is the feasible way of reutilization of Laojun Cave.

\section{A. Physical Geography Landscape}

The physic-geographical environment is a significant part of the unique historic landscape. It is the environmental element breeding the peculiar local customs and humanistic spirit. Such physic-geographical environment also contains the environment integrating human and nature after the processing by human in the past ages. Only by protecting the architecture and its environment, can it fully reflect the original function and position. The protection of the historical landscape of Laojun Cave may continue the original characteristic landscape.

\section{B. The Unique Street Space}

It is the basic element of the county, as well as the specific reflection of the texture and character of the county, including the layout form, road traffic, public activity space and horizontal contour line formed by the historic architectures. The width and orientation of Fushan County still maintain the original layout, the architectures on both sides of the street also continue the forms of traditional quadrangle dwellings. The streets and lanes around Laojun Cave shall try to maintain the original landscape. For the well-preserved traditional quadrangle dwellings, it shall keep the styles and features on the original foundation, and facilities can be added in appropriate ways to satisfy the life demands. As for the newly-built architectures that destruct the texture of streets, it shall be renovated or reconstructed, and the ultrahigh part shall be dismantled. The damaged and collapsing architectures shall be reutilized in proper means, and the color and style shall be in line with traditional forms in color and style, and it shall not be too large in size. In order to protect effectively and update properly, necessary analysis shall be conducted for the space features of the streets and lanes, to control the roof forms, height and facet styles, etc. of significant architectures.

\section{Historical Building Entity}

Laojun Cave is a significant building with important historic information. The original authentic historical object and its remaining complete historic information shall be protected. The renovation shall stick to the principle "renovate as it was and restore the authenticity", and the restoration shall use the original material and technology to attain the original taste and restore the original features.

\section{CONCLUSION}

In the protection of Laojun Cave, it is necessary to adequately embody the mutual relationship among cultural relic, historical environment and existing environment, to guarantee the security, reality and integrity of cultural relic and historical environment; Furthermore, it also needs to give full active play of cultural relics to cultural environment in this area, and try best to achieve the harmonious development on the whole.

The historical building of towns and villages has historic and cultural value, and it also has social and economic value. Since it can only development with the society by getting further into the modern social life, or it may be eliminated. Such reutilization protection is an approach for the historical and cultural heritage to be vital in modern life, and it can turn the negative protection to be positive protection. When it is reutilized, it shall readjust itself and get accustomed to the requirements of new functions in new stage through reasonable updating and renovation, so as to gain the vitality of survival and development. It is an effective approach for the everlasting existence in the long history.

\section{REFERENCES}

[1] Cao Jianye, Study on the Protection and Reutilization of Ancient City in Shanxi[D]. Shenyang Jianzhu University, 2011. 